\title{
A near-infrared ratiometric fluorescent probe for cysteine detection over glutathione indicating mitochondrial oxidative stress in vivo
}

\author{
Kun Yin ${ }^{\mathrm{a}, \mathrm{b}}$, Fabiao $\mathrm{Yu}^{\mathrm{a}, *}$, Weiwei Zhang ${ }^{\mathrm{a}, \mathrm{c}}$, Lingxin Chen ${ }^{\mathrm{a}, *}$ \\ ${ }^{a}$ Key Laboratory of Coastal Environmental Processes and Ecological Remediation; The Research Center for Coastal Environmental Engineering and Tech- \\ nology, Yantai Institute of Coastal Zone Research, Chinese Academy of Sciences, Yantai 264003, China \\ ${ }^{\mathrm{b}}$ University of Chinese Academy of Sciences, Beijing 100049, China \\ ' School of Marine Sciences, Ningbo University, Ningbo 315211, China
}

\section{A R T I C L E I N F O}

\section{Article history:}

Received 6 April 2015

Received in revised form

2 June 2015

Accepted 17 June 2015

Available online 20 June 2015

\section{Keywords:}

Cysteine

Ratiometric fluorescence

Image analysis

Mitochondria

Oxidative stress

\begin{abstract}
A B S T R A C T
We establish a near-infrared (NIR) ratiometric fluorescent probe Cy-NB for the selective detection of cysteine (Cys) over glutathione (GSH) and homocysteine (Hcy) in mitochondria to indicate oxidative stress. Heptamethine cyanine dye is chosen as the fluorophore of Cy-NB whose emission locates in NIR region. And p-nitrobenzoyl is employed as the fluorescent modulator due to its capability of selective-Cys response. Once triggered by Cys, the uncaged p-nitrobenzoyl rearranges the polymethine $\pi$-electron system of the fluorophore, which leads to a remarkable spectrum shifts in absorption and emission profiles. Taking advantage of these spectroscopic properties, we construct a ratiometric fluorescent signal for the detection of Cys with a detection limit of $0.2 \mu \mathrm{M}$ within $5 \mathrm{~min}$. Our probe Cy-NB can sensitively detect the mitochondrial Cys pool changes under different oxidative stress status in HepG2 cells. We also successfully employ Cy-NB to imaging Cys level changes in living mice. It suggests that mitochondrial Cys can be used as an oxidative stress biomarker with simple potential clinical applications. And our probe $\mathrm{Cy}-\mathrm{NB}$ is of great potential for further utilizing in exploring the physiological function of Cys in biological systems.
\end{abstract}

(c) 2015 Elsevier B.V. All rights reserved.

\section{Introduction}

As one of the intracellular biothiols, cysteine (Cys) plays vital roles in various metabolic processes of human beings, such as catalysis, heavy metal binding, protein turnover, and signal transduction (Reddie and Carroll, 2008). Along with glutathione (GSH), Cys holds important redox pool to regulate reactive oxygen species (ROS) homeostasis, which mainly occurs on mitochondria respiratory chain (Balaban et al., 2005; Schwarzländer and Finkemeier, 2013). The mitochondrial dynamic antioxidant defenses network by Cys is independent on GSH system. Compared with the GSH, Cys is more effective to be oxidized (Jones et al., 2004). And Cys can translate to CySS for defending oxidative stress preferentially when cells are confronted with oxidative stress and ROS can be tightly regulated (Winterbourn, 2008). Furthermore, Cys is also a limiting factor for GSH synthesis which also plays a significant role in the maintenance of redox status (Vincent et al., 1999). All the above aspects reveal that mitochondrial Cys is a key factor for mitochondrial oxidative stress defense. And the

\footnotetext{
* Corresponding authors. Fax: +865352109130.

E-mail addresses: fbyu@yic.ac.cn (F. Yu), lxchen@yic.ac.cn (L. Chen).
}

concentration of Cys is very significant and sensitive to mitochondrial oxidative stress (Armstrong et al., 2004). Once ROS are over-produced and over-whelm the antioxidant defenses capacities, there will be a rapidly depletion of mitochondrial Cys, and then the mitochondrial oxidative stress occurs, which further leads to variety of diseases including Alzheimer's disease, Parkinson's disease and neurodegenerative diseases (Markesbery, 1997; Yee et al., 2014). That is, the levels of mitochondrial Cys can be applied to indicate oxidative stress status potentially. Therefore, it is crucially and urgently to develop specific fluorescence probes for the detection of mitochondrial Cys.

To date, various methods have been established to detect Cys such as colorimetry, electrochemical techniques, and fluorescence methods (Zhang et al., 2007; Lee et al., 2008; Pu et al., 2010; Jung et al., 2012; Kong et al., 2013; Dai et al., 2014; Su et al., 2014; Wang et al., 2015). Compared with other technologies, the fluorescent methods possess high sensitivity, less invasiveness and real-time imaging, which are of great advantage to analyze Cys in cells (Lin et al., 2008; Li et al., 2009, 2013; Long et al., 2011; Lu et al., 2011; Yuan et al., 2011; Wang et al., 2012a,2012b; Yin et al., 2013; Zhu et al., 2014). However, there still remains quite a challenge to distinguish mitochondrial Cys from GSH, because the 
concentrations of mitochondrial Cys $(\sim 500 \mu \mathrm{M})$ are much lower than those of GSH ( $\sim 10 \mathrm{mM})$ (Ubuka et al., 1992). Additionally, even the low concentration of mitochondrial Hcy $(\sim 50 \mathrm{nM})$ in cells, the similar structure of Hcy with Cys makes it a competitive interference which cannot be ignored in the detection of mitochondrial Cys. Therefore, the desirable probe should function exclusively to Cys detection over GSH and Hcy in cells.

In this work, we report a ratiometric near-infrared (NIR) fluorescent probe $\mathrm{Cy}-\mathrm{NB}$ for the detection of mitochondrial Cys over GSH and Hcy. The probe Cy-NB exhibits a rapid colorimetric and ratiometric fluorescence response to mitochondrial Cys by modulating the polymethine $\pi$-electron system. The ratiometric signal allows the determination at two emission channels and provides a built-in correction to avoid environment interference (Ueno and Nagano, 2011). Utilizing these advantages, we employ $\mathrm{Cy}-\mathrm{NB}$ to detect mitochondrial Cys in living cells. The probe Cy-NB can be used to monitor mitochondrial Cys level changes successfully under different oxidative stress status in living cells. Additionally, as a NIR fluorescent probe, Cy-NB owns great advantages for bioimaging for its ability to avoid the autofluorescence of organisms and detect deeply into tissues (Escobedo et al., 2010). We also utilize Cy-NB to image Cys level changes in living mice.

\section{Materials and methods}

\subsection{Chemicals and instruments}

Unless stated otherwise, all chemicals used in synthesis are analytical reagent grade. Milli-Q water $(18.2 \mathrm{M} \Omega \mathrm{cm})$ was used. Thin-layer chromatography (TCL) was performed on silica gel plates. Silica gel P60 (SiliCycle) was used for column chromatography (Hailang, Yantai) 200-300 mesh. UV-vis spectra were measured on a $\mu$-Quant microplate reader Nanodrop 2000C (Thermo Scientific, USA) with a $1 \mathrm{~cm}$ quartz cell. Fluorescence spectra were quantitatively measured by FluoroMax-4 spectrofluorometer with a xenon lamp and $0.5 \mathrm{~cm}$ quartz cells. High-resolution mass spectra were carried on LCQ Fleet LC-MS System (Thermo Fisher Scientific). ${ }^{1} \mathrm{H}$ NMR, ${ }^{13} \mathrm{C}$ NMR spectra were carried on a Bruker spectrometer. The fluorescence images of HepG2 cells were taken by a confocal laser scanning microscope (Japan Olympus Co., Ltd) with an objective lens $(\times 60)$. The fluorescence images of living BALB/c mice were obtained by in vivo imaging system (Bruker). All pH were determined by ph-3 m (Lei Ci Device Works, Shanghai, China).

\subsection{Synthesis}

\subsubsection{Synthesis of ketone-CY}

Heptacyanine Cy.7.Cl (230 mg, $0.45 \mathrm{mmol}$ ) which has already been synthesized in our laboratory (Wang et al., 2012a,2012b) and sodium acetate (100 mg, $1.2 \mathrm{mmol}$ ) which dissolved in anhydrous $\mathrm{N}, \mathrm{N}$-dimethylformamide $(15 \mathrm{~mL})$ were heated at $90{ }^{\circ} \mathrm{C}$ for $6 \mathrm{~h}$ under Ar atmosphere. After the mixture cooled to the room temperature, the crude mixture was filtered, concentrated and evaporated under reduced pressure and subsequently dried with vacuum pumping to obtain red product. Then the ketone-Cy $(150 \mathrm{mg})$ was purified by silica chromatography eluted with $\mathrm{CH}_{2} \mathrm{Cl}_{2} / \mathrm{CH}_{3} \mathrm{OH}(8: 2, \mathrm{v} / \mathrm{v}) .{ }^{1} \mathrm{H}$ NMR $\left(500 \mathrm{MHz}, \mathrm{CDCl}_{3}-\mathrm{D}_{1}\right) \delta(\mathrm{ppm})$ : 7.65-7.63 (d, 2H), 7.46-7.44 (d, 2H), 6.66-6.94 (m, 2H), 6.90-6.76 $(t, 2 \mathrm{H}), 6.50-6.46(m, 2 \mathrm{H}), 4.24-4.22(m, 2 \mathrm{H}), 3.70-3.67(m, 4 \mathrm{H})$, $2.53-2.51(t, 4 \mathrm{H}), 1.74-1.66(s, 12 \mathrm{H}), 1.41-1.35(m, 2 \mathrm{H}), 1.29-1.26(t$, $6 \mathrm{H}) .{ }^{13} \mathrm{C}$ NMR $\left(125 \mathrm{MHz}, \mathrm{CDCl}_{3}-\mathrm{D}_{1}\right) \delta$ (ppm): 190.37, 178.05, 139.02, 131.23, 130.92, 128.84, 127.57, 122.03, 121.86, 109.30, 97.60, 65.57, 30.58, 29.66, 29.36, 24.36, 22.69, 14.12, 13.73. LC-MS (ESI $\left.{ }^{+}\right)$: $m / z \mathrm{C}_{34} \mathrm{H}_{40} \mathrm{~N}_{2} \mathrm{O}$ calcd. 492.3141, found $[\mathrm{M}+\mathrm{H}]^{+}$493.3217. Elemental analysis calculated (\%) for $\mathrm{C}_{34} \mathrm{H}_{40} \mathrm{~N}_{2} \mathrm{O}$ : C, 82.9; $\mathrm{H}, 8.2 ; \mathrm{N}$, 5.7; O, 3.2; found: C, 88.8; $\mathrm{H}, 8.3$; N, 5.6; O, 3.3.

\subsubsection{Synthesis of $C Y-N B$}

Compound 1 (100 mg, $0.19 \mathrm{mmol})$ and triethylamine $(278 \mu \mathrm{L}$, $0.6 \mathrm{mmol}$ ) were dissolved in $15 \mathrm{~mL}$ anhydrous $\mathrm{CH}_{2} \mathrm{Cl}_{2}$ at $0{ }^{\circ} \mathrm{C}$, then p-nitrobenzoyl chloride $(10 \mathrm{~mL})$ was added dropwise and kept stirring at $0{ }^{\circ} \mathrm{C}$ for $30 \mathrm{~min}$. Then the mixture was warmed to room temperature and stirred overnight. The solution was diluted with $\mathrm{CH}_{2} \mathrm{Cl}_{2}(30 \mathrm{~mL})$ for extraction operation. The solvent was removed in vacuo to obtain a crude mixture deep green solid. Finally, $\mathrm{Cy}-\mathrm{NB}$ was isolated by silica chromatography eluting with $\mathrm{CH}_{2} \mathrm{Cl}_{2} / \mathrm{CH}_{3} \mathrm{OH}$ $(8: 2, \mathrm{v} / \mathrm{v})$ as a green solid (40 mg, $38 \%$ yield). ${ }^{1} \mathrm{H}$ NMR $(500 \mathrm{MHz}$, $\left.\mathrm{C}_{2} \mathrm{D}_{6} \mathrm{SO}_{\mathrm{D}} \mathrm{D}_{6}\right) \delta: 8.58-8.54(\mathrm{~m}, 3 \mathrm{H}), 7.72-7.17(\mathrm{~m}, 8 \mathrm{H}), 6.23-6.21(\mathrm{~d}$, $1 \mathrm{H}), 4.91(\mathrm{~s}, 1 \mathrm{H}), 4.32-4.29(\mathrm{~m}, 3 \mathrm{H}), 4.14-4.11(\mathrm{~m}, 2 \mathrm{H}), 3.47(\mathrm{~m}$, $2 \mathrm{H}), 2.04(t, 4 \mathrm{H}), 1.43-1.24(m, 20 \mathrm{H}) .{ }^{13} \mathrm{C}$ NMR $(125 \mathrm{MHz}$, $\left.\mathrm{C}_{2} \mathrm{D}_{6} \mathrm{SO}-\mathrm{D}_{6}\right) \delta(\mathrm{ppm}): 171.16,162.21,158.99,151.63,141.65,140.81$, $139.81,133.36,131.30,128.93,128.81,125.36,124.55,122.12$, $122.09,110.82,100.77,65.53,60.36,48.94,39.86,30.54,27.87$, 24.61, 21.02, 20.76, 19.16, 14.17, 13.70, 12.41. LC-MS (ESI+): $\mathrm{m} / \mathrm{z}$ $\mathrm{C}_{41} \mathrm{H}_{44} \mathrm{~N}_{3} \mathrm{O}_{4}{ }^{+}$calcd 642.3326, found [M+] 642.3326. Elemental analysis calculated (\%) for $\mathrm{C}_{41} \mathrm{H}_{44} \mathrm{~N}_{3} \mathrm{O}_{4}{ }^{+}$: C, 76.6; $\mathrm{H}, 6.9 ; \mathrm{N}, 6.5 ; \mathrm{O}$, 10.0; found: C, 76.7; H, 6.8; N, 6.6; O, 9.9.

\subsubsection{Synthesis of $C Y-B$}

Compound 1 (100 mg, $0.19 \mathrm{mmol})$ and triethylamine $(278 \mu \mathrm{L}$, $0.6 \mathrm{mmol}$ ) were dissolved in $15 \mathrm{~mL}$ anhydrous $\mathrm{CH}_{2} \mathrm{Cl}_{2}$ at $0{ }^{\circ} \mathrm{C}$, then benzoyl chloride $(10 \mathrm{~mL})$ was added dropwise and kept stirring at $0{ }^{\circ} \mathrm{C}$ for $30 \mathrm{~min}$. Then the mixture was warmed to room temperature and stirred overnight. The solution was diluted with $\mathrm{CH}_{2} \mathrm{Cl}_{2}(30 \mathrm{~mL})$ for extraction operation. The solvent was removed in vacuo to obtain a crude mixture deep green solid. Finally, Cy-B was isolated by silica chromatography eluting with $\mathrm{CH}_{2} \mathrm{Cl}_{2} / \mathrm{CH}_{3} \mathrm{OH}$ $(8: 2, \mathrm{v} / \mathrm{v})$ as a green solid (40 mg, $42 \%$ yield). ${ }^{1} \mathrm{H}$ NMR $(500 \mathrm{MHz}$, $\left.\mathrm{C}_{2} \mathrm{D}_{6} \mathrm{SO}_{\mathrm{D}} \mathrm{D}_{6}\right) \delta:$ 8.35-8.33 $(\mathrm{m}, 1 \mathrm{H}), 7.72-7.22(\mathrm{~m}, 11 \mathrm{H}), 6.13-6.10(\mathrm{~m}$, $1 \mathrm{H}), 4.31-4.28(m, 5 \mathrm{H}), 4.15-4.06(m, 3 \mathrm{H}), 2.61(m, 4 \mathrm{H}), 1.74-1.25$ $(m, 20 \mathrm{H}) .{ }^{13} \mathrm{C}$ NMR $\left(125 \mathrm{MHz}, \mathrm{C}_{2} \mathrm{D}_{6} \mathrm{SO}^{\left.-\mathrm{D}_{6}\right)} \delta: 167.66,141.59,140.91\right.$, 140.76, 135.05, 132.27, 130.91, 130.13, 128.80, 125.29, 122.17, 110.59, 100.16, 65.51, 50.40, 48.98, 41.00, 30.53, 27.79, 24.52, 23.71, 23.36, 19.14, 13.70. LC-MS (ESI+): $m / z \quad \mathrm{C}_{41} \mathrm{H}_{45} \mathrm{~N}_{2} \mathrm{O}_{2}{ }^{+}$calcd 597.3476, found $[\mathrm{M}+]$ 597.3479. Elemental analysis calculated (\%) for $\mathrm{C}_{41} \mathrm{H}_{45} \mathrm{~N}_{2} \mathrm{O}_{2}{ }^{+}$: C, 82.4; H, 7.6; N, 4.7; O, 5.3; found: C, 82.3; H, 7.7; $\mathrm{N}, 4.5 ; \mathrm{O}, 5.5$.

\subsection{Spectroscopic data}

The probe Cy-NB, Cy-B, Rhodamine123 dye, Hoechst 33258 dye were solute in dimethyl sulfoxide (DMSO) and maintained in refrigerator at $4^{\circ} \mathrm{C}$. Stock solutions $(1.0 \mathrm{mM})$ of amino acids including cysteine (Cys), homocysteine (Hcy), glutathione (GSH), cysteine (CySS), alanine (Ala), arginine (Arg), glycine (Gly), isoleucine (Ile), lysine (Lys), proline (Pro), serine (Ser), and valine (Val) were prepared in twice-distilled water. Absorption spectra were obtained with $1.0-\mathrm{cm}$ cuvette cells. The probe $\mathrm{Cy}-\mathrm{NB}$ was added to a 10.0-mL color comparison tube. After dilution to $0.5 \mu \mathrm{M}$ with $5 \mathrm{mM}$ HEPES buffer, different concentrations of Cys were added. The mixture was incubated at $37^{\circ} \mathrm{C}$ for $5 \mathrm{~min}$ before measurement. Fluorescence spectra were obtained with a $1.0-\mathrm{cm}$ quartz cells by Xenon lamp. The probe $\mathrm{Cy}-\mathrm{NB}$ was added to a $10.0-\mathrm{mL}$ color comparison tube. After diluted to $0.5 \mu \mathrm{M}$ with $5 \mathrm{mM}$ HEPES buffer, different concentrations of Cys were added. The mixture was incubated at $37^{\circ} \mathrm{C}$ for 5 min before measurement. 


\subsection{Cell culture and confocal imaging}

HepG2 cells were seeded at a density of $1 \times 10^{6}$ cells $\mathrm{mL}^{-1}$ in RPMI 1640 Medium supplemented with $10 \%$ fetal bovine serum (FBS), $\mathrm{NaHCO}_{3}(2 \mathrm{~g} / \mathrm{L})$, and $1 \%$ antibiotics (penicillin/streptomycin, $100 \mathrm{U} / \mathrm{ml}$ ). Cultures were maintained at $37^{\circ} \mathrm{C}$ under a humidified atmosphere containing $5 \% \mathrm{CO}_{2} / 95 \%$ air. The cells were sub-cultured by scraping and seeding on $18 \mathrm{~mm}$ glass coverslips in culture dish. The fluorescence images of HepG2 cells were taken by a confocal laser scanning microscope (Japan Olympus Co., Ltd) with an objective lens $(\times 60)$. Excitation of HepG2 cells at $559 \mathrm{~nm}$ and $635 \mathrm{~nm}$ were carried out with a HeNe laser and the emission was collected from $580 \mathrm{~nm}$ to $680 \mathrm{~nm}$ and $700 \mathrm{~nm}$ to $800 \mathrm{~nm}$, respectively. In the case of mitochondria and nucleus staining, excitation at $405 \mathrm{~nm}$ and $515 \mathrm{~nm}$ the emission was collected from $420 \mathrm{~nm}$ to $480 \mathrm{~nm}$ and $520 \mathrm{~nm}$ to $550 \mathrm{~nm}$, respectively.

\subsection{Fluorescent imaging in living mice}

All the BALB/c mice were selected and divided into two groups. In the control group a, the peritoneal cavities of BALB/c mice were injected with $50 \mu \mathrm{L}$ solution (DMSO/saline $=1: 9, \mathrm{v} / \mathrm{v}$ ). And the $\mathrm{BALB} / \mathrm{c}$ mice in group b were injected into their peritoneal cavities with $50 \mu \mathrm{L} 1 \mathrm{mM}$ Cys (DMSO/saline $=1: 9, \mathrm{v} / \mathrm{v}$ ). Thirty minutes later, the probe $\mathrm{Cy}-\mathrm{NB}(1 \mu \mathrm{M}, 50 \mu \mathrm{L}$ in $1: 9 \mathrm{DMSO} /$ saline $\mathrm{v} / \mathrm{v})$ was injected into peritoneal cavities of the two group $\mathrm{BALB} / \mathrm{c}$ mice for another $30 \mathrm{~min}$. Fluorescence images were constructed from fluorescence collection channel $1\left(600 \mathrm{~nm}\right.$ to $700 \mathrm{~nm}, \lambda_{\mathrm{ex}}$ $=530 \mathrm{~nm})$ and channel $2\left(750 \mathrm{~nm}\right.$ to $\left.850 \mathrm{~nm}, \lambda_{\mathrm{ex}}=735 \mathrm{~nm}\right)$ using in vivo imaging system (Bruker). Additionally, we merged the fluorescence image with the corresponding X-ray image to clearly display the reaction site of the mice.

\section{Results and discussion}

\subsection{Design of $C Y-N B$}

We have developed a ratiometric near-infrared fluorescent probe $\mathrm{Cy}-\mathrm{NB}$ for mitochondrial Cys detection with a high signalto-noise $(S / N)$ ratio. We choose heptamethine cyanine as fluorophore for its NIR emission, high molar absorption coefficient, low biological toxicity, good biocompatibility and mitochondria-selectivity. And p-nitrobenzoyl is equipped as the modulator which selectively responds to Cys. Cyanine dye mainly exists as ketone-cy under physiological conditions. While integrated with p-nitrobenzoyl, the ketone-cy changed to enol form and the spectrum properties is changed obviously by modulating the intramolecular polymethine $\pi$-electron system (Guo et al., 2012). Once triggered by Cys, the cyanine dye can be released from Cy-NB and comes back to ketone-cy form which recovers the polymethine $\pi$-electron system (Scheme 1). Therefore, this spectrum property of cyanine makes the probe Cy-NB exhibit a remarkable emission shift and sensitive to Cys.

\subsection{Proposed detection mechanism of $C Y-N B$}

The proposed detection mechanism of probe $\mathrm{Cy}-\mathrm{NB}$ for the detection of Cys is shown in Scheme S1. After Cys added into the solution, the ester of $\mathrm{Cy}-\mathrm{NB}$ is selectively attacked by the sulfydryl of Cys, which releases the ketone-cy fluorophore. The cleavage of p-nitrobenzoyl behaves intramolecular rearrangement to yield $\mathrm{N}$-substituted product and followed by the intramolecular cyclization to complete the reaction (Tanaka et al., 2004; Yang et al., 2012; Lv et al., 2014). It is known that sulfydryl and amino group are both nucleophilic groups in aminothiols. In order to verify that the selectively detection of Cys is caused by sulfydryl, several control experiments are implemented from different aspects. As shown in Fig. S1, the probe Cy-NB could response to $100 \mu \mathrm{M} \beta$ mercaptoethanol rapidly but could not response to $100 \mu \mathrm{M}$ ethanolamine. The result confirms that the cleavage of ester is induced by sulfydryl but not amino group. And the sulfydryl of Cys can elevate the nucleophilic ability of amino group (about $10^{3}$ times) (Burchfield, 1958), which results in intramolecular rearrangement of compound 3 (Scheme S1). Furthermore, the absorption spectra of Cy-NB were examined in the presence of Cys, CySS, Hcy and GSH. An obvious absorption hypsochromic shift was observed with adding $100 \mu \mathrm{M}$ Cys but the absorption spectra of Cy-NB showed no differences in the presence of equal CySS, Hcy and GSH (Fig. S2). In the case of CySS, the sulfydryl is hidden in disulfide bond, which cannot induce the reaction with Cy-NB. As for Hcy and GSH, which are also aminothiols, but the $\mathrm{pK}_{\mathrm{a}}$ of Hcy (10.00) and GSH (9.20) are higher than that of Cys (8.53) (Benesch and Benesch, 1955). The nucleophilic ability of sulfydryl in Hcy and GSH is much weaker than that of Cys, which agrees with our previous research (Yin et al., 2015). In addition, the bulkiness of tripeptide of GSH would significantly hinder the reaction activity of sulfydryl. Therefore, the response of Cy-NB to Cys will not be interferenced by Hcy and GSH. These results further indicate that the sulfydryl is the key point that triggers $\mathrm{Cy}-\mathrm{NB}$ response to Cys

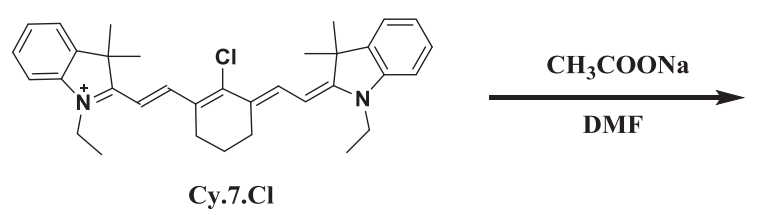

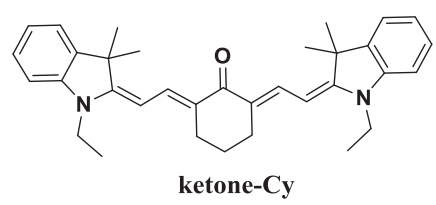

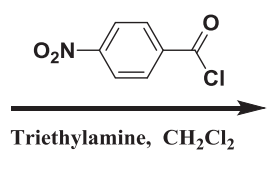

ketone-Cy

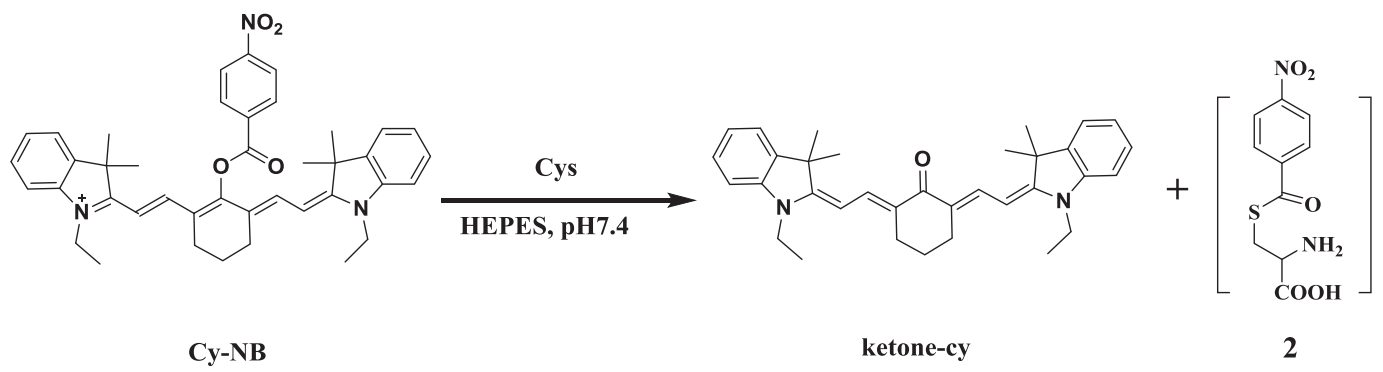

Scheme 1. Synthesis route of Cy-NB and its reaction with Cys. 
selectively. Furthermore, to investigate the function of nitro group in our probe, a control probe Cy-B was synthesized (Scheme S2). Both the probe $\mathrm{Cy}-\mathrm{NB}$ and $\mathrm{Cy}-\mathrm{B}$ were incubated with $50 \mu \mathrm{M}$ Cys at $37^{\circ} \mathrm{C}$ for $5 \mathrm{~min}$. The spectrum property of probe $\mathrm{Cy}-\mathrm{NB}$ was changed obviously but that of $\mathrm{Cy}-\mathrm{B}$ showed almost no changes (Fig. S3). We suggest that the nitro group which performed as a strong electron-withdrawing group can facilitate the ester cleavage and the cyanine dye can be uncaged easily from $\mathrm{Cy}$-NB after Cys attacked. Therefore, the probe Cy-NB achieves rapidly response of Cys with the assistance of nitro group. And the fast response of Cy-NB to Cys is expected to detect mitochondrial Cys level changes and be able to assess oxidative stress in living cells.

\subsection{Parameter optimization of the probe for Cys detection}

We optimized the reaction conditions of probe $\mathrm{Cy}-\mathrm{NB}$ for the detection of Cys. Buffer solution, $\mathrm{pH}$ and reaction time were taken into consideration. As buffer solution plays an important role in the performance of Cy-NB, HEPES, MOPS and Tris- $\mathrm{HCl}$ were investigated for their effect on the detection of Cys by Cy-NB. As shown in Fig. S4, the response of Cy-NB to Cys was the best in $5 \mathrm{mM}$ HEPES. In addition, the stability of Cy-NB was good from $\mathrm{pH}$ 4.0 to $\mathrm{pH} 8.0$ but glided sharply when $\mathrm{pH}$ exceeds 8.0 for the deprotonation of nitrogen atom. As the probe worked well under physiological conditions so $\mathrm{pH} 7.4$ was chosen. And the complete reaction of Cys and Cy-NB could be almost obtained within 5 min. Furthermore, the fluorescence property of probe Cy-NB could remain stable over 60 min under the reaction condition (Fig. S5). Therefore, the detection of Cys by probe $\mathrm{Cy}-\mathrm{NB}$ was reacted in $5 \mathrm{mM}$ HEPES, pH 7.4 and incubated at $37^{\circ} \mathrm{C}$ for $5 \mathrm{~min}$.

\subsection{Spectral properties of CY-NB towards Cys}

\subsubsection{Absorbance spectral analysis}

We examined the absorption spectral properties of $\mathrm{Cy}-\mathrm{NB}$ in $5 \mathrm{mM}$ HEPES solutions, pH 7.4. As shown in Fig. 1a, the UV-vis absorption of probe Cy-NB was centered at $780 \mathrm{~nm}(\varepsilon$ $=1.2 \times 10^{6} \mathrm{M}^{-1} \mathrm{~cm}^{-1}$ ), which displayed a green color. However, a new absorption peak at $500 \mathrm{~nm}\left(\varepsilon=2.4 \times 10^{5} \mathrm{M}^{-1} \mathrm{~cm}^{-1}\right)$ appeared and increased gradually after the probe $\mathrm{Cy}-\mathrm{NB}$ incubated with different concentrations of Cys at $37{ }^{\circ} \mathrm{C}$ for $5 \mathrm{~min}$. The color of the solution changed to red with the generation of the ketone-cy. The obvious absorption hypsochromic shift (about $280 \mathrm{~nm}$ ) indicated that the polymethine $\pi$-electron system of $\mathrm{Cy}-\mathrm{NB}$ was changed after triggered by Cys. These results show that the probe can be employed for Cys detection by naked eyes.

\subsubsection{Fluorescence spectral analysis}

We next investigated the fluorescence spectra of the probe $\mathrm{Cy}$ NB. The emission peak of probe Cy-NB is $785 \mathrm{~nm}\left(\lambda_{\mathrm{ex}}=720 \mathrm{~nm}\right)$. After Cy-NB incubated with Cys at $37{ }^{\circ} \mathrm{C}$ for $5 \mathrm{~min}$, a new emission peak at $640 \mathrm{~nm}\left(\lambda_{\mathrm{ex}}=560 \mathrm{~nm}\right)$ was observed. The large hypsochromic shift confirms that the $\pi$-electron system of Cy-NB is reassigned by the transformation from enol form to ketone form. Utilizing the principle, the NIR ratiometric detection of Cys can be accomplished with Cy-NB by the ratio of $F_{640} \mathrm{~nm}\left(\lambda_{\mathrm{ex}}=560 \mathrm{~nm}\right)$ to $F_{785} \mathrm{~nm}\left(\lambda_{\mathrm{ex}}=720 \mathrm{~nm}\right)$. Compared to those probes with single emission wavelength, the result achieved by $\mathrm{Cy}-\mathrm{NB}$ is more sensitive and accurate because the signal of ratiometric probe is independent of probe concentration, photobleaching, and illumination intensity in the biological samples. These advantages inspire us to explore the property of Cy-NB for the detection of Cys by ratiometric signal. We incubated our probe Cy-NB with $0,5,10,15$, $20,25,30,35,40,45,50,75$ and $100 \mu \mathrm{M}$ Cys in $5 \mathrm{mM}$ HEPES at $\mathrm{pH}$
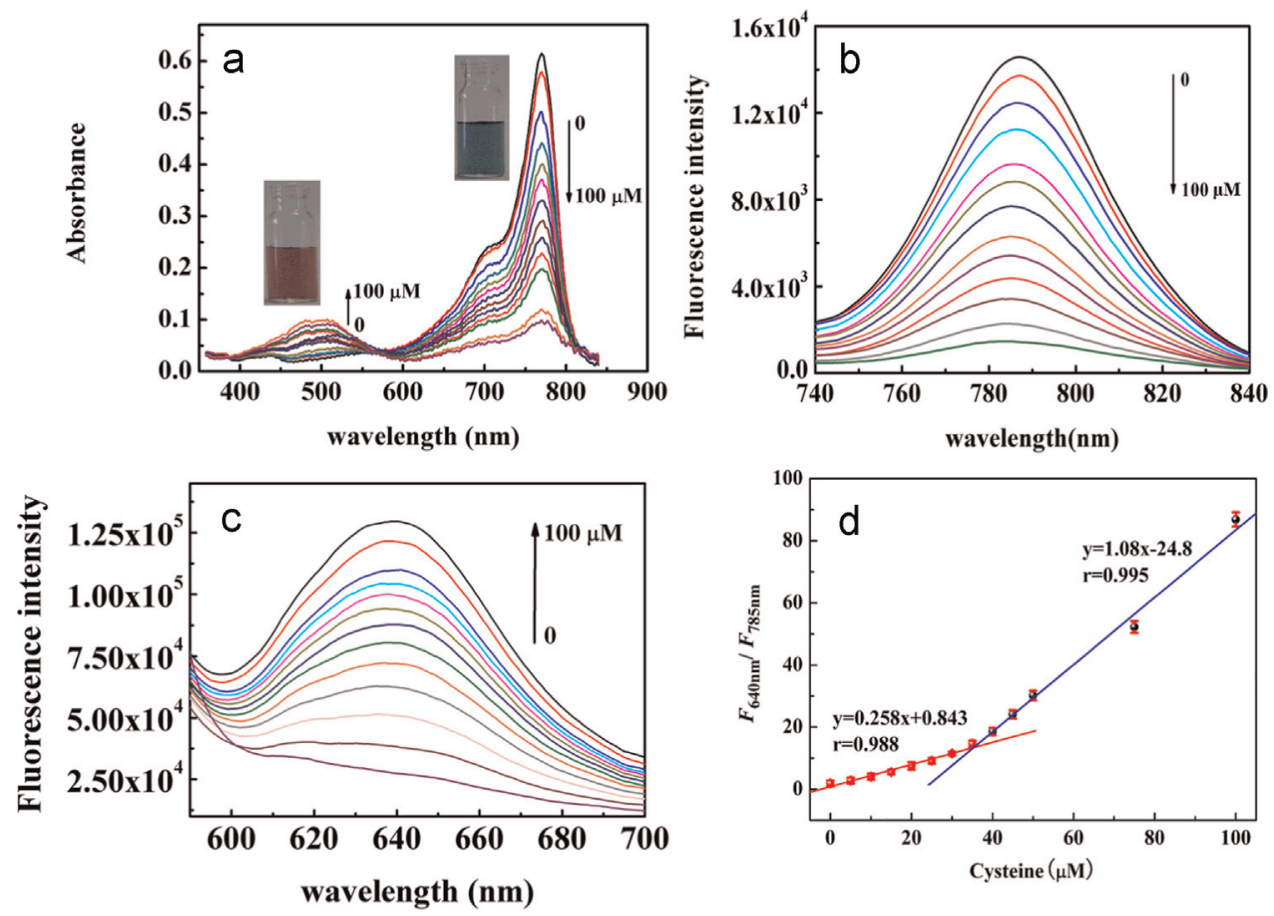

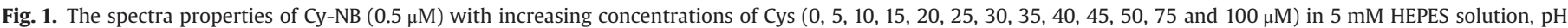

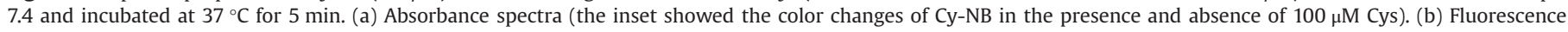

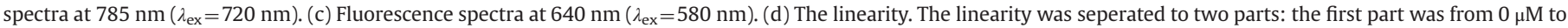

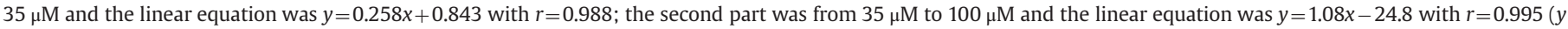

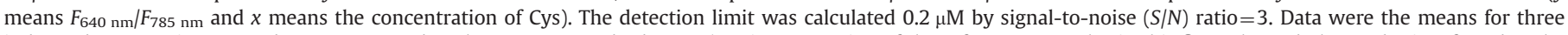

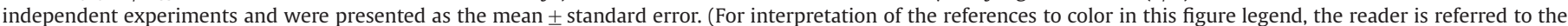
web version of this article.) 
7.4 for 5 min. As shown in Fig. 1b, the emission peak at $785 \mathrm{~nm}\left(\lambda_{\text {ex }}\right.$ $=720 \mathrm{~nm}$ ) of probe Cy-NB was decreased with the increase of Cys concentration. Meantime, the emission peak at $640 \mathrm{~nm}\left(\lambda_{\text {ex }}\right.$ $=560 \mathrm{~nm}$ ) was increased gradually (Fig. 1c). The results showed that the fluorescence ratio $\left(F_{640} \mathrm{~nm} / F_{785} \mathrm{~nm}\right)$ increased from 1.9 to 84.9, with a 45-fold enhancement. In addition, good linearity of emission ratios $\left(F_{640 \mathrm{~nm}} / F_{785} \mathrm{~nm}\right)$ in the range of $0-35 \mu \mathrm{M}$ and 35$100 \mu \mathrm{M}$ was exhibited respectively (Fig. 1d). The detection limit was $0.2 \mu \mathrm{M}$, which was calculated by $S / N$ ratio $=3$. The high ratio signal of Cy-NB to Cys is benefited from the modulation of polymethine $\pi$-electron system which results a large hypsochromic shift of emission band. Then the analyses of Cys in spiked cell lysis samples were carried out by our probe, high performance liquid chromatography (HPLC) and liquid chromatography tandem mass spectrometry (LC-MS) (Hoogerheide and Campbell, 1992; Huang et al., 2011). As shown in Table S1, the accuracy of quantitative analysis by the probe Cy-NB are lower than HPLC/LC-MS methods. But the results of our probe agreed well with those obtained by HPLC and LC-MS for the detection of Cys in cell lysis samples. Compared with the probes have already be established (Table S3), our probe $\mathrm{Cy}-\mathrm{NB}$ provides rapid response time of Cys with satisfactory sensitivity. These advantages make Cy-NB an efficient candidate to detect endogenous mitochondrial Cys level changes.

\subsection{Selectivity of CY-NB to Cys}

\subsubsection{Selectivity of CY-NB to Cys in water solution}

To investigate the selectivity of Cy-NB towards Cys, the probe was incubated with various species such as Cys, Hcy, N-Acetyl-Lcysteine (NAC), 2-Methyl-L-cysteine (MC), Cys-Gly, GSH and other amino acids in $5 \mathrm{mM}$ HEPES buffer at $\mathrm{pH}$ 7.4. As shown in Fig 2a, $100 \mu \mathrm{M}$ Hcy, $10 \mathrm{mM}$ GSH and other amino acids showed little interference in the detection of Cys by Cy-NB. Even though the concentration of mitochondrial GSH is much higher than that of Cys, the probe $\mathrm{Cy}-\mathrm{NB}$ owns the ability to distinguish mitochondrial Cys from GSH. The concentration of mitochondrial Hcy ( $\sim 50 \mathrm{nM})$ is much lower than that of Cys $(\sim 500 \mu \mathrm{M})$, which means that Hcy cannot make any interference in the detection of mitochondrial Cys. The ratiometric response $\left(F_{640 \mathrm{~nm}} / F_{785} \mathrm{~nm}\right)$ of probe $\mathrm{Cy}-\mathrm{NB}$ was observed in presence of NAC. Although an acetyl group is attached to the amino group of NAC, the structure of NAC is quite similar to Cys. There exists free thiol in NAC. And NAC has been widely utilized as antioxidant in vivo (Sandstrom et al., 1994; Bilodeau et al., 2001). However, the reactivity of the thiol in NAC is reduced by the acetyl group. Therefore, the probe $\mathrm{Cy}-\mathrm{NB}$ can respond to NAC, but the response of NAC by the probe Cy-NB is weaker than that of Cys. The phenomenon was further verified that the detection of Cys by $\mathrm{Cy}-\mathrm{NB}$ was induced by sulfydryl but not amino group. Considering that the concentrations of Cys in cell lysis samples were much higher than those of NAC (Table S2), which were consistent with the results obtained by Wu et al. (2005), the NAC would not influence the detection of Cys at cell lysis level (Fig. S6). Therefore, the detection of Cys by our probe Cy-NB would not be influenced by NAC in living cells. All the results indicate that our probe $\mathrm{Cy}-\mathrm{NB}$ exhibits excellent selectivity for Cys over other kinds of biothiols and amino acids. Furthermore, we examined the time-dependent emission ratio $\left(F_{640} \mathrm{~nm} / F_{785} \mathrm{~nm}\right)$ changes of Cy-NB $(0.5 \mu \mathrm{M})$ in the presence of Cys $(100 \mu \mathrm{M})$, Hcy $(100 \mu \mathrm{M})$, GSH $(10 \mathrm{mM})$, NAC $(100 \mu \mathrm{M}), \mathrm{MC}(100 \mu \mathrm{M})$ and Cys-Gly $(100 \mu \mathrm{M})$, respectively (Fig. 2b). There are almost no signal obtained from Cy-NB in the presence of GSH, MC and Cys-Gly with almost no emission ratio change. The emission ratio of Cy-NB toward Hcy displayed a little variation from 1.86 to 6.11 during $10 \mathrm{~min}$. By comparison, the response of the probe Cy-NB to Cys exhibited an obvious emission ratio $\left(F_{640 \mathrm{~nm}} / F_{785 \mathrm{~nm}}\right)$ leap from 1.9 to 84.9 within 5 min. Even though the response of the probe $\mathrm{Cy}-\mathrm{NB}$ to $100 \mu \mathrm{M}$ NAC also
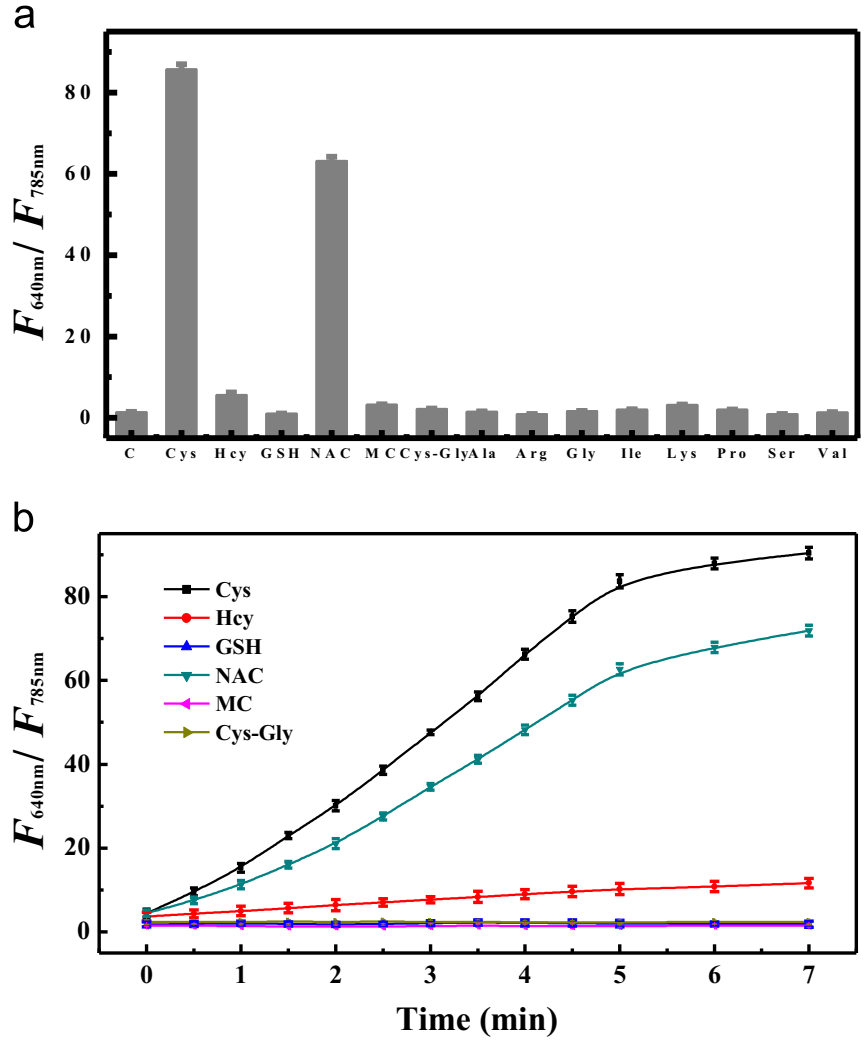

Fig. 2. (a) The ratiometric response $\left(F_{640 \mathrm{~nm}} / F_{785} \mathrm{~nm}\right)$ of Cy-NB $(0.5 \mu \mathrm{M})$ to Cys and other amino acids in $5 \mathrm{mM}$ HEPES solution, $\mathrm{pH} 7.4$ and incubated at $37{ }^{\circ} \mathrm{C}$ for $5 \mathrm{~min}$. C means control (none amino acids exist), Cys $(100 \mu \mathrm{M})$, Hcy $(100 \mu \mathrm{M}), \mathrm{GSH}$ $(10 \mathrm{mM})$, NAC $(100 \mu \mathrm{M}), \mathrm{MC}(100 \mu \mathrm{M})$, Cys-Gly $(100 \mu \mathrm{M})$ and other amino acids $(10 \mathrm{mM})$. (b) Time-dependent ratiometric response $\left(F_{640 \mathrm{~nm}} / F_{785} \mathrm{~nm}\right)$ of Cy-NB $(0.5 \mu \mathrm{M})$ to Cys $(100 \mu \mathrm{M}), \mathrm{Hcy}(100 \mu \mathrm{M}), \mathrm{GSH}(10 \mathrm{mM}), \mathrm{NAC}(100 \mu \mathrm{M}), \mathrm{MC}(100 \mu \mathrm{M})$ and Cys-Gly $(100 \mu \mathrm{M})$, respectively. Data were the means for three independent experiments and were presented as the mean \pm standard error.

exhibited an emission ratio $\left(F_{640 \mathrm{~nm}} / F_{785} \mathrm{~nm}\right)$ leap from 1.98 to 63.7 within $5 \mathrm{~min}$, but NAC would not influence the detection of Cys under physiological condition. Next, we determined the reaction kinetics with excessive amounts of Cys, Hcy, GSH, NAC, MC and Cys-Gly towards Cy-NB in 5 mM HEPES at pH 7.4 and incubated at $37^{\circ} \mathrm{C}$. Herein, the reaction kinetics followed the pseudo-first-order kinetics and the rate constant $k$ was calculated by Eq. (1):

$\ln \left[\left(F_{\max }-F_{t}\right) / F_{\max }\right]=-k t$

where $F_{\max }$ means fluorescence intensities at $640 \mathrm{~nm}$ at the maximum value and $F_{t}$ means the fluorescence intensities at time $t$. The rate constant $k$ for Cys, Hcy, GSH, NAC, MC and Cys-Gly is $9.3 \times 10^{-2} \mathrm{~min}^{-1}, 1.2 \times 10^{-3} \mathrm{~min}^{-1}, 2.8 \times 10^{-4} \mathrm{~min}^{-1}, 6.9 \times 10^{-2} \mathrm{~min}^{-1}$, $2.6 \times 10^{-4} \mathrm{~min}^{-1}$ and $3.3 \times 10^{-4} \mathrm{~min}^{-1}$, respectively. The pseudo-firstorder reaction constant $k$ for Cys is almost 330 -fold faster than that of GSH, 78-fold faster than Hcy, 1.3-fold faster than NAC, 360-fold faster than MC and 280-fold faster than Cys-Gly. All the results clearly indicate that the probe Cy-NB is an outstanding ratiometric fluorescent probe for the selective detection of Cys over GSH, Hcy, MC and CysGly. The selectivity of our probe Cy-NB is not good for NAC, but considering that the concentration of NAC is much lower than Cys in living cells, it will not influence the detection of Cys.

\subsubsection{Selectivity of $C Y-N B$ to Cys in living cells}

We next studied whether the probe Cy-NB can respond to Cys without interference in living cells or not. The living HepG2 cells were chosen as bioassay model to evaluate the selectivity of $\mathrm{Cy}-\mathrm{NB}$ toward Cys in living cells. The living HepG2 cells were incubated in 
the presence of Cys $(200 \mu \mathrm{M})$, Hcy $(200 \mu \mathrm{M}), \mathrm{GSH}(10 \mathrm{mM})$ and other amino acids $(10 \mathrm{mM})$ respectively at $37^{\circ} \mathrm{C}$ for $30 \mathrm{~min}$. The pre-treated cells were washed by RPMI-1640 three times and then incubated with $1 \mu \mathrm{M} \mathrm{Cy}-\mathrm{NB}$ at $37^{\circ} \mathrm{C}$ for another $5 \mathrm{~min}$. Confocal ratiometric fluorescence images of living HepG2 cells were obtained by the ratio of emission intensities from $580 \mathrm{~nm}$ to $680 \mathrm{~nm}$ $\left(\lambda_{\mathrm{ex}}=559 \mathrm{~nm}\right)$ and from $700 \mathrm{~nm}$ to $800 \mathrm{~nm}\left(\lambda_{\mathrm{ex}}=635 \mathrm{~nm}\right)$. As shown in Fig. S6b, when the HepG2 cells pre-incubated with $200 \mu \mathrm{M}$ Cys, the ratio image was much brighter than control group (Fig. S7a). However, the ratio images showed almost no difference when HepG2 cells pre-incubated with $10 \mathrm{mM} \mathrm{GSH}, 200 \mu \mathrm{M}$ Hcy and $10 \mathrm{mM}$ other amino acids (Fig. S7c-S7l). These results verified that the response of Cy-NB to Cys is also specific in living HepG2 cells.

\subsection{Cytotoxicity of CY-NB to Cys}

We also performed the MTT assays to estimate the cytotoxicity of Cy-NB. As shown in Fig. S8, the cellular viability was about 85\% even in the presence of $10 \mu \mathrm{M} C y-N B$ at $37^{\circ} \mathrm{C}$ for $12 \mathrm{~h}$ which indicated the low cytotoxicity of our probe.

\subsection{Mitochondrial sub-location of CY-NB}

Mitochondria are known as power plant as well as a cellular compartment which proceeds various biosynthetic pathways. However, these important life-supporting mitochondria are also linked to death-promoting activity of cells (Newmeyer and Ferguson-Miller, 2003). As a kind of by-products of oxidative phosphorylation on mitochondria, ROS lead to mitochondrial oxidative stress and play a vital role in apoptosis regulation (Simon et al., 2000). As an important antioxidant defender, mitochondrial Cys level is sensitive to ROS. We next confirmed that our probe Cy-NB can be used to monitor mitochondrial Cys level to access mitochondrial oxidative stress. As mentioned above, the probe $\mathrm{Cy}-\mathrm{NB}$ displayed excellent properties in the detection of Cys with great sensitivity and selectivity both in solution and living cells. We evaluated the ability of probe $\mathrm{Cy}$-NB to sub-locate on mitochondria as the Cy-NB achieves the ability to target mitochondria for its ammonium cation (Wang et al., 2013). We utilized co-localization experiments which were usually employed for describing the difference of the location between two or more molecular dyes to validate Cy-NB located in mitochondria (Yu et al., 2013). As shown in Fig. 3, the living HepG2 cells were co-stained with $1 \mu \mathrm{M}$ Cy-NB (5 min), $5 \mu \mathrm{M}$ Rhodamine 123 (a mitochondria dye, $15 \mathrm{~min}$ ) and $2 \mu \mathrm{M}$ Hoechst 33258 (a nuclear dye, $30 \mathrm{~min}$ ) (Crissman and Hirons, 1994). Fluorescence confocal microscopic image of probe CyNB, Rhodamine 123 and Hoechst 33258 was constructed from $580 \mathrm{~nm}$ to $680 \mathrm{~nm}\left(\lambda_{\mathrm{ex}}=559 \mathrm{~nm}\right)$, from $520 \mathrm{~nm}$ to $550 \mathrm{~nm}\left(\lambda_{\text {ex }}\right.$ $=515 \mathrm{~nm})$ and from 420 to $480 \mathrm{~nm}\left(\lambda_{\mathrm{ex}}=405 \mathrm{~nm}\right)$, respectively. Fig. $3 a_{1}$ is co-localization image of Cy-NB and Hoechst 33258 and Fig. $3 a_{2}$ is co-localization image of Rhodamine 123 and Hoechst 33258. Then we merged Fig. $3 a_{1}$ and $a_{2}$ to form co-localization image of three dyes (Fig. $3 a_{3}$ ). Rhodamine 123 has already been confirmed with excellent quality of mitochondria localization in living cells (Johnson et al., 1980). As shown in Fig. 3a 3 , the image of Cy-NB merged well with that of staining with the Rhodamine 123 dye in discrete subcellular locations. And we evaluated the Pearson's coefficient $R_{\mathrm{r}}=0.96$ and the Manders' coefficients $m_{1}=0.99$, $m_{2}=0.98$ by the Image-Pro Plus software. The intensity distributions of the two co-localization dyes were demonstrated through counting the intensity of color-pair feature pixel to reveal their correlation (Fig. $3 b_{1}-b_{3}$ ). As shown in Fig. $3 b_{3}$, the probe Cy-NB displaying a highly correlated plot with Rodamine 123 . In addition, the intensity profiles of linear regions of the interest across HepG2 cells (white arrow in Fig. $3 a_{3}$ ) further proved Cy-NB and Rhodamine 123 depicted a good synchrony. All above results verify that the probe Cy-NB offers excellent ability to locate in mitochondria.

\subsection{Assessment of mitochondrial oxidative stress status}

We next examined the ability of $\mathrm{Cy}-\mathrm{NB}$ to assess oxidative stress status in mitochondria. In the control group, the living HepG2 cells were incubated with $1 \mu \mathrm{M}$ Cy-NB at $37^{\circ} \mathrm{C}$ for 5 min. Then HepG2 cells were washed with RPMI-1640 three times before image acquisition. Confocal ratiometric fluorescence images of living HepG2 cells were obtained by the ratio of emission intensities from $580 \mathrm{~nm}$ to $680 \mathrm{~nm}\left(\lambda_{\mathrm{ex}}=559 \mathrm{~nm}\right)$ and from $700 \mathrm{~nm}$ to $800 \mathrm{~nm}\left(\lambda_{\mathrm{ex}}=635 \mathrm{~nm}\right)$. As shown in Fig. 4a, a clear fluorescence ratio image was obtained which indicated that our probe was able
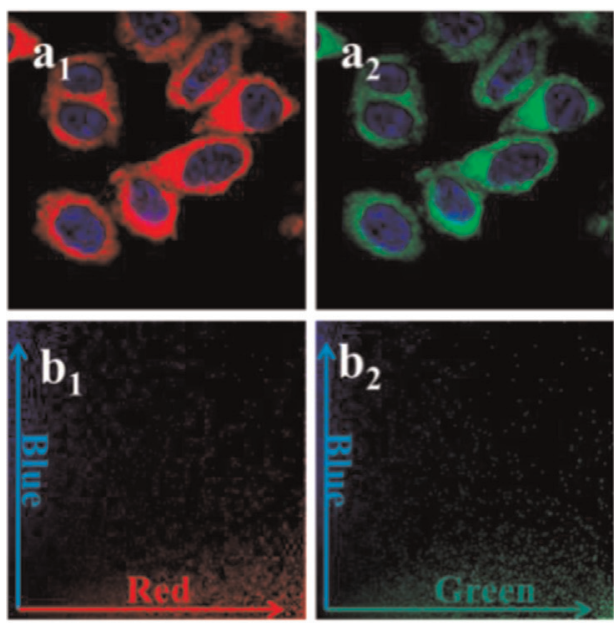
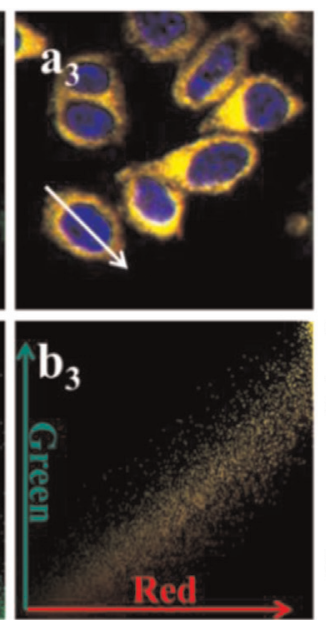

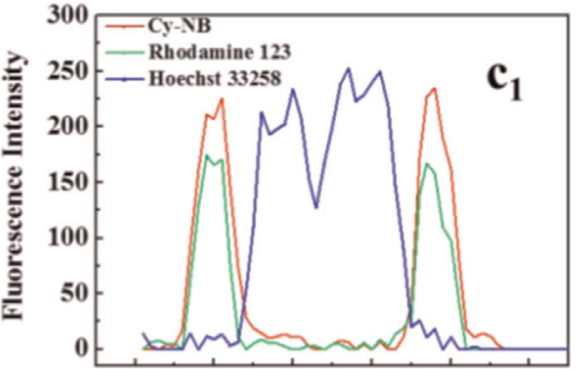

Pixel Distance

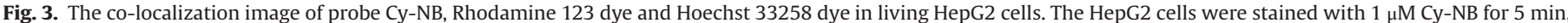

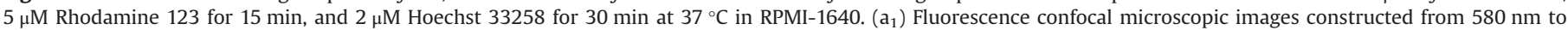

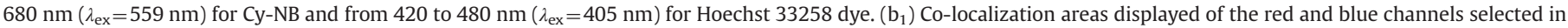

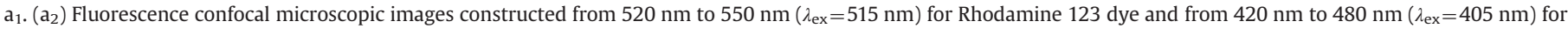

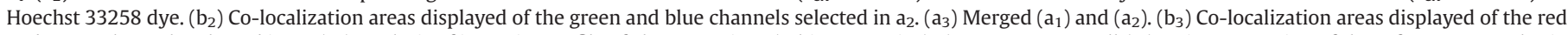

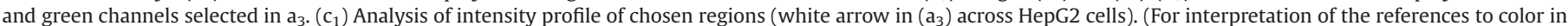
this figure legend, the reader is referred to the web version of this article.) 

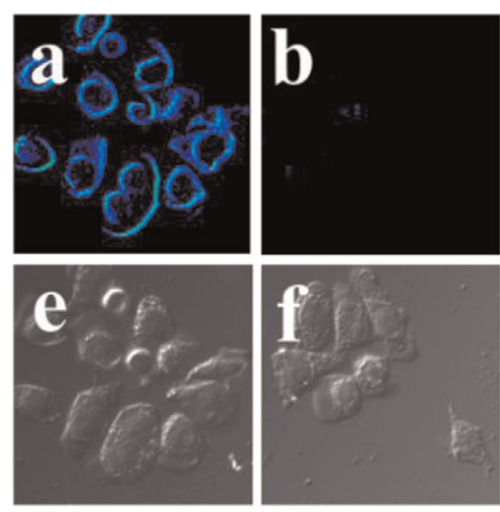
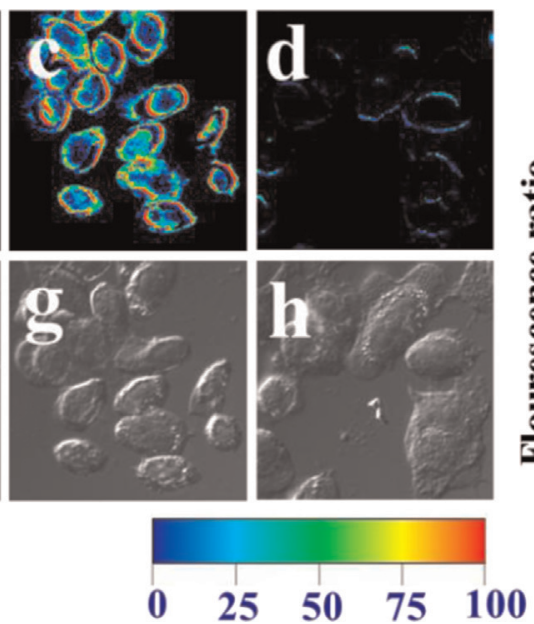

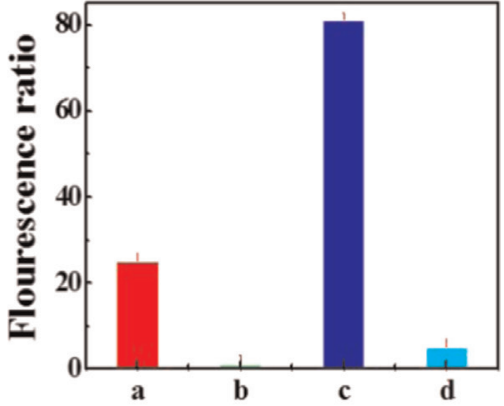

\section{0}

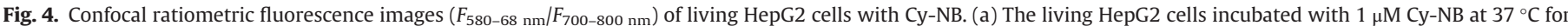

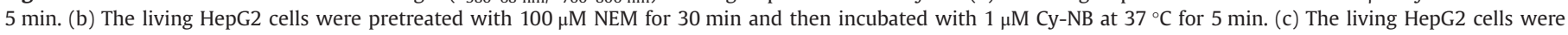

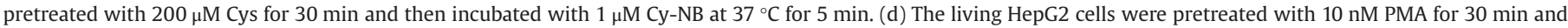

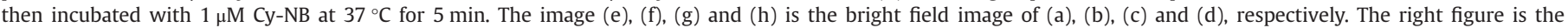
quantification of fluorescence ratio of each group. Data were the means for three independent experiments and were presented as the mean \pm standard error.

to detect endogenous mitochondria Cys. In the group two, the living HepG2 cells were pretreated with $100 \mu \mathrm{M}$ N-ethyl-maleimide (NEM, a thiol blocking reagent) for $30 \mathrm{~min}$ and then incubated with $1 \mu \mathrm{M}$ Cy-NB at $37^{\circ} \mathrm{C}$ for $5 \mathrm{~min}$. As shown in Fig. $4 \mathrm{~b}$, the fluorescence ratio image was almost black and the fluorescence ratio changed from 25.0 (Fig. 4a) to 1.5 (Fig. 4b) after mitochondrial Cys consumed by NEM. In the group three, the living HepG2 cells were pre-treated with $200 \mu \mathrm{M}$ Cys for $30 \mathrm{~min}$ and followed incubated with $1 \mu \mathrm{M} \mathrm{Cy}-\mathrm{NB}$ at $37^{\circ} \mathrm{C}$ for $5 \mathrm{~min}$. As shown in Fig. 4c, the fluorescence ratio of living HepG2 cells changed to 80.0. In the group four, the living HepG2 cells were pre-treated with $10 \mathrm{nM}$ phorbol 12-myristate 13-acetate (PMA) for $30 \mathrm{~min}$ to induce mitochondrial oxidative stress by respiratory burst (Emerit and Cerutti, 1982) and then incubated with $1 \mu \mathrm{M}$ Cy-NB at $37^{\circ} \mathrm{C}$ for $5 \mathrm{~min}$. As shown in Fig. 4d, the fluorescence ratio of HepG2 cells pretreated by PMA was calculated to be 6.0 , which was much lower than control group (Fig. 4a). As described above, the detection limit of probe Cy-NB is not as good as traditional methods like LC-MS. It meets big challenge for exactly quantifying the Cys concentration in living cells by the probe Cy-NB. However, the above results demonstrated that the mitochondrial Cys level decreased obviously after intracellular oxidative stress and our probe Cy-NB could monitor this alteration successfully. All these results confirm that $\mathrm{Cy}-\mathrm{NB}$ is an excellent ratiometric fluorescent probe for mitochondrial Cys detection and can be utilized to assess mitochondrial oxidative stress successfully.

\subsection{Visualization of Cys levels in living mice}

We further tested the ability of Cy-NB to detect Cys in living animals, since the NIR emission of $\mathrm{Cy}-\mathrm{NB}$ can penetrate deep tissue and avoid background autofluorescence. We chose BALB/c mice as the biological model and divided them into four groups. In the control group a, the peritoneal cavities of BALB/c mice were injected with $50 \mu \mathrm{L}$ solution (DMSO/saline $=1: 9, \mathrm{v} / \mathrm{v}$ ). The BALB/c mice in group b-d were intraperitoneally injected with $50 \mu \mathrm{L}$ $1 \mathrm{mM}$ Cys, $50 \mu \mathrm{L} \quad 1 \mathrm{mg} / \mathrm{mL}$ lipopolysaccharide and $100 \mu \mathrm{L}$ $10 \mathrm{mg} / \mathrm{mL}$ diethylmaleate (DMSO/saline $=1: 9, \mathrm{v} / \mathrm{v}$ ), respectively. Thirty minutes later, the probe Cy-NB $(1 \mu \mathrm{M}, 50 \mu \mathrm{L}$ in $1: 9 \mathrm{DMSO} /$ saline $\mathrm{v} / \mathrm{v}$ ) was injected into peritoneal cavities of the four group $\mathrm{BALB} / \mathrm{c}$ mice for another $30 \mathrm{~min}$. Fluorescence images were constructed from fluorescence collection channel 1 (600 nm to $\left.700 \mathrm{~nm}, \lambda_{\mathrm{ex}}=530 \mathrm{~nm}\right)$ and channel $2\left(750 \mathrm{~nm}\right.$ to $850 \mathrm{~nm}, \lambda_{\mathrm{ex}}$
$=735 \mathrm{~nm}$ ) using in vivo imaging system (Bruker). Additionally, we merged the fluorescence image with the corresponding X-ray image to clearly display the reaction site of the mice. In the control group a, a recognizable signal was collected in channel 2 (Fig. $5 \mathrm{a}_{2}$ ), which indicated that our probe $\mathrm{Cy}-\mathrm{NB}$ had reacted with endogenous Cys in peritoneal cavity of BALB/c mice. In the group b, the signal intensity in channel 1 was decreased obviously (mean signal intensity changed from 163.7 to 37.2) after exogenous Cys added into the peritoneal cavity (Fig. $5 b_{1}$ ). Meanwhile, the mean signal intensity collected in channel 2 was increased from 295.7 to 1435.4, which confirmed that Cy-NB could detect Cys level changes in peritoneal cavity of BALB/c mice (Fig. $5 b_{2}$ ). As shown in Fig. $5 c_{2}$, the signal of Cy-NB collected in channel 2 was much weaker than that of group a. The result indicated that the concentration of Cys in the peritoneal cavity of mice was decreased under oxidative stress condition, which induced by lipopolysaccharide (Kheir-Eldin et al., 2001) and the result agreed with previous research (Iyer et al., 2009). In the group d, the signal of Cy-NB collected in channel 2 was also weaker than that of group a, which indicated that the Cys in mice peritoneal cavities were depleted after diethylmaleate treated and the results agreed with Gerard-Monnier et al. (1992). All these results verify that our probe $\mathrm{Cy}-\mathrm{NB}$ is able to image endogenous Cys level in living animals.

\section{Conclusions}

In summary, a near-infrared ratiometric fluorescent probe $\mathrm{Cy}$ NB for the detection of mitochondrial Cys has been developed. The probe $\mathrm{Cy}-\mathrm{NB}$ is able to selectively respond Cys in aqueous solution, in living cells and in vivo. The triggered rearrangement of the conjugated $\pi$-electron system in fluorophore will produce a ratiometric fluorescent signal that allows avoiding environment interference. The mitochondria-targeted probe $\mathrm{Cy}-\mathrm{NB}$ exhibits excellent properties including fast reaction kinetics, good selectivity, high sensitivity, and good photostability. Our probe reveals that the endogenous mitochondrial Cys pool will vary under different oxidative stress status. We also achieve imaging Cys in mice successfully. The promising ratiometric NIR fluorescent probe can be of great potential for further utilizing in investigating the physiological function of Cys in biological systems. 


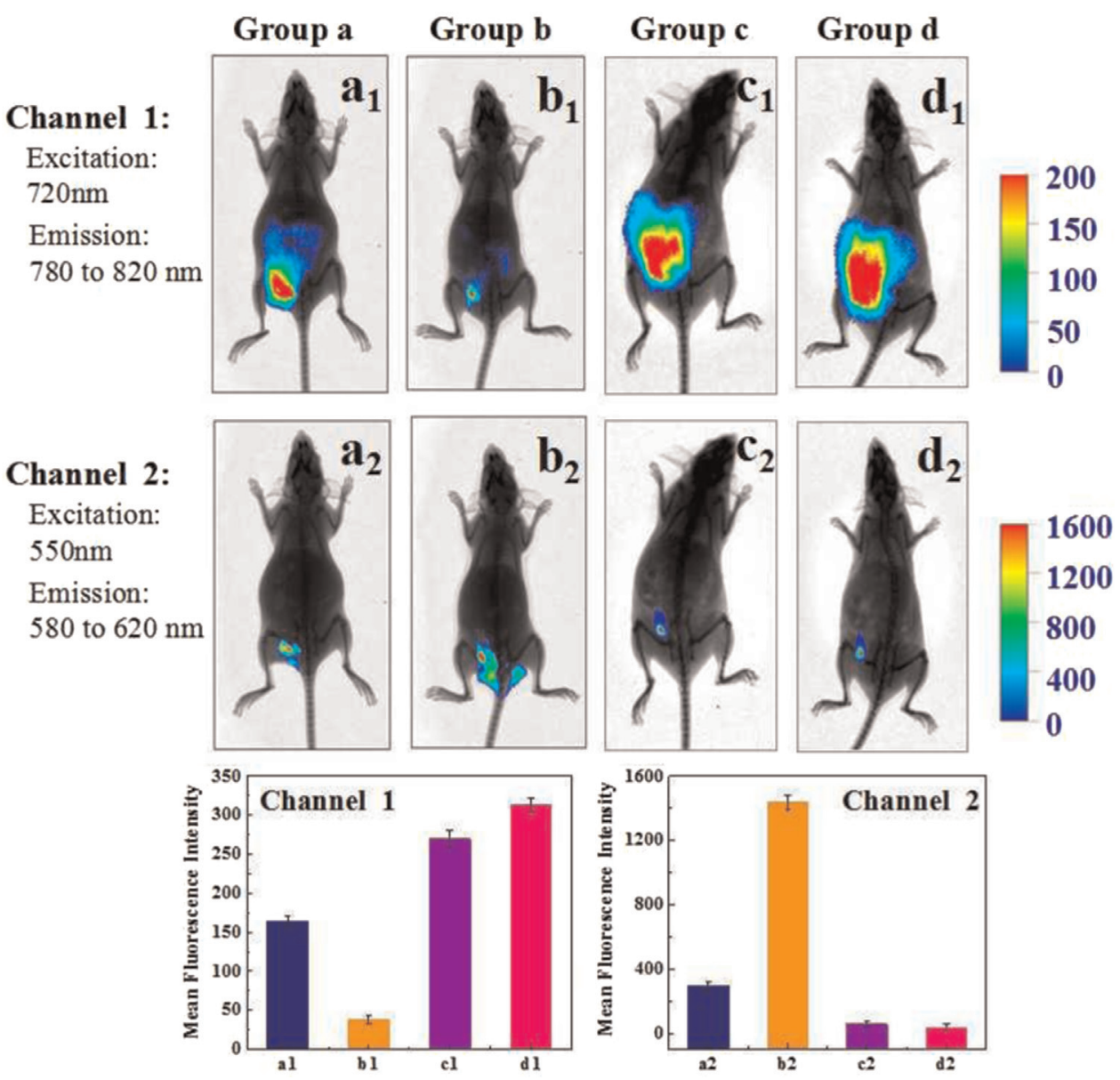

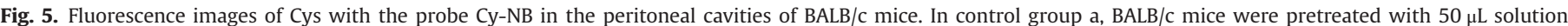

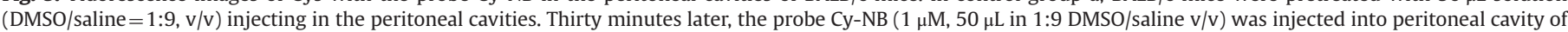

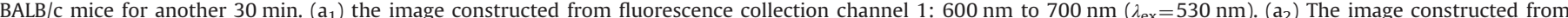

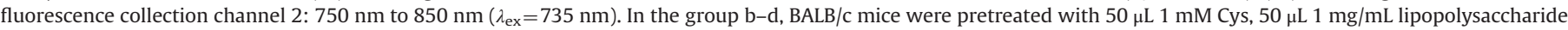

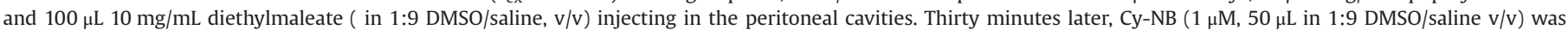

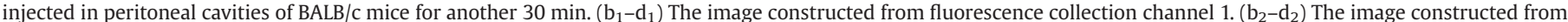

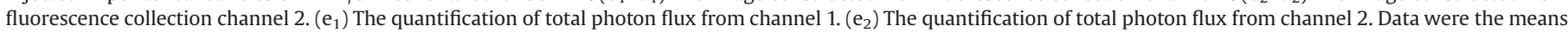
for three independent experiments and were presented as the mean \pm standard error.

\section{Acknowledgments}

We thank the Project of on-site sediment microbial remediation of public area of central Bohai Sea, North China Sea Branch of State Oceanic Administration (Grant QDZC20150420-002), the National Natural Science Foundation of China Nos. 31200041, 21405172 and 21275158, Innovation Project of the CAS (Grant KZCX2-EW-206), the Key Research Program of the CAS (Grant KZZD-EW-14) and the Grant Sponsor Youth Innovation Promotion Association (Grant 2015170).

\section{Appendix A. Supplementary Information}

Supplementary data associated with this article can be found in the online version at doi:10.1016/j.bios.2015.06.039.

\section{References}

Armstrong, J.S., Whiteman, M., Yang, H., Jones, D.P., Sternberg, P., 2004. Investig. Ophthalmol. Vis. Sci. 45, 4183-4189.

Balaban, R.S., Nemoto, S., Finkel, T., 2005. Cell 120, 483-495.

Benesch, R.E., Benesch, R., 1955. J. Am. Chem. Soc. 77, 5877-5881.

Bilodeau, J.F., Blanchette, S., Gagnon, C., Sirard, M.A., 2001. Theriogenology 56,
275-286.

Burchfield, H., 1958. Nature 181, 49-50.

Crissman, H.A., Hirons, G.T., 1994. Methods Cell Biol. 41, 195-209.

Dai, X., Wu, Q., Wang, P., Tian, J., Xua, Y., Wang, S., Miao, J., Zhao, B., 2014. Biosens. Bioelectron. 59, 35-39.

Emerit, I., Cerutti, P.A., 1982. Proc. Natl. Acad. Sci. USA 79, 7509-7513.

Escobedo, J.O., Rusin, O., Lim, S., Strongin, R.M., 2010. Curr. Opin. Chem. Biol. 14 64-70.

Gerard-Monnier, D., Fougeat, S., Chaudiere, J., 1992. Biochem. Pharmacol. 43, 451-456.

Guo, Z., Nam, S., Park, S., Yoon, J., 2012. Chem. Sci. 3, 2760-2765.

Hoogerheide, J.G., Campbell, C.M., 1992. Anal. Biochem. 201, 146-151.

Huang, Y.Q., Ruan, G.D., Liu, J.Q., Gao, Q., Feng, Y.Q., 2011. Anal. Biochem. 416, 159-166.

Iyer, S.S., Jones, D.P., Brigham, K.L., Rojas, M., 2009. Am. J. Respir. Cell Mol. 40, 90-98.

Johnson, L.V., Walsh, M.L., Chen, L.B., 1980. Proc. Natl. Acad. Sci. USA 77, 990-994. Jones, D.P., Go, Y.-M., Anderson, C.L., Ziegler, T.R., KINKADE, J.M., Kirlin, W.G., 2004. FASEB J. 18, 1246-1248.

Jung, H.S., Pradhan, T., Han, J.H., Heo, K.J., Lee, J.H., Kang, C., Kim, J.S., 2012. Biomaterials 33, 8495-8502.

Kheir-Eldin, A.A., Motawi, T.K., Gad, M.Z., Abd-ElGawad, H.M., 2001. Int. J. Biochem. Cell B 33, 475-482.

Kong, F., Liu, R., Chu, R., Wang, X., Xu, K., Tang, B., 2013. Chem. Commun, 49, 9176-9178.

Lee, J.-S., Ulmann, P.A., Han, M.S., Mirkin, C.A., 2008. Nano Lett. 8, 529-533.

Li, H., Fan, J., Wang, J., Tian, M., Du, J., Sun, S., Sun, P., Peng, X., 2009. Chem. Commun., 5904-5906.

Li, X., Gao, X., Shi, W., Ma, H., 2013. Chem. Rev. 114, 590-659.

Lin, W., Long, L., Yuan, L., Cao, Z., Chen, B., Tan, W., 2008. Org. Lett. 10, 5577-5580. Long, L., Lin, W., Chen, B., Gao, W., Yuan, L., 2011. Chem. Commun. 47, 893-895.

Lu, J., Sun, C., Chen, W., Ma, H., Shi, W., Li, X., 2011. Talanta 83, 1050-1056. 
Lv, H., Yang, X.-F., Zhong, Y., Guo, Y., Li, Z., Li, H., 2014. Anal. Chem. 86, 1800-1807. Markesbery, W.R., 1997. Free Radic. Bio. Med. 23, 134-147.

Newmeyer, D.D., Ferguson-Miller, S., 2003. Cell 112, 481-490.

Pu, F., Huang, Z., Ren, J., Qu, X., 2010. Anal. Chem. 82, 8211-8216.

Reddie, K.G., Carroll, K.S., 2008. Curr. Opin. Chem. Biol. 12, 746-754.

Sandstrom, P.A., Mannie, M.D., Buttke, T.M., 1994. J. Leukoc. Biol. 55, 221-226.

Schwarzländer, M., Finkemeier, I., 2013. Antioxid. Redox Signal. 18, 2122-2144.

Simon, H.-U., Haj-Yehia, A., Levi-Schaffer, F., 2000. Apoptosis 5, 415-418.

Su, D., Teoh, C.L., Sahu, S., Das, R.K., Chang, Y.-T., 2014. Biomaterials 35, 6078-6085.

Tanaka, F., Mase, N., Barbas Iii, C.F., 2004. Chem. Commun., 1762-1763.

Ubuka, T., Ohta, J., Yao, W.-B., Abe, T., Teraoka, T., Kurozumi, Y., 1992. Amino Acids 2, $143-155$.

Ueno, T., Nagano, T., 2011. Nat. Methods 8, 642-645.

Vincent, B.Rd.S., Mousset, Jacquemin, S., Sablon, A., 1999. Eur. J. Bio-chem. 262, 873-878.

Wang, K., Oian, J., Jiang, D., Yang, Z., Du, X., Wang, K., 2015. Biosens, Bioelectron. 63, $112-116$.

Wang, R., Chen, L., Liu, P., Zhang, Q., Wang, Y., 2012a. Chem. Eur. J. 18, 11343-11349. Wang, R., Yu, F., Chen, L., Chen, H., Wang, L., Zhang, W., 2012b. Chem. Commun. 48,
$11757-11759$

Wang, X., Sun, J., Zhang, W., Ma, X., Lv, J., Tang, B., 2013. Chem. Sci. 4, 2551-2556. Winterbourn, C.C., 2008. Nat. Chem. Biol. 4, 278-286.

Wu, W., Goldstein, G., Adams, C., Matthews, R.H., Ercal, N., 2005. Biomed. Chromatogr. 20, 415-422.

Yang, Z., Zhao, N., Sun, Y., Miao, F., Liu, Y., Liu, X., Zhang, Y., Ai, W., Song, G., Shen, X. Yu, X., Sun, J., Wong, W., 2012. Chem. Commun. 48, 3442-3444.

Yee, C., Yang, W., Hekimi, S., 2014. Cell 157, 897-909.

Yin, C., Huo, F., Zhang, J., Martínez-Máñez, R., Yang, Y., Lv, H., Li, S., 2013. Chem. Soc. Rev. 42, 6032-6059.

Yin, K., Li, B., Wang, X., Zhang, W., Chen, L., 2015. Biosens. Bioelectron. 64, 81-87. Yu, F., Li, P., Wang, B., Han, K., 2013. J. Am. Chem. Soc 135, 7674-7680.

Yuan, L., Lin, W., Yang, Y., 2011. Chem. Commun. 47, 6275-6277.

Zhang, M., Yu, M., Li, F., Zhu, M., Li, M., Gao, Y., Li, L., Liu, Z., Zhang, J., Zhang, D., Yi, T., Huang, C., 2007. J. Am. Chem. Soc. 129, 10322-10323.

Zhu, B., Guo, B., Zhao, Y., Zhang, B., Du, B., 2014. Biosens. Bioelectron. 55, 72-75. 